\title{
Microbiological Quality of Prawns Collected from Local Markets of Dhaka Metropolis
}

\author{
Anindita Bhowmik, Sharmistha Goswami and Sunjukta Ahsan* \\ Department of Microbiology, University of Dhaka, Dhaka 1000, Bangladesh
}

\begin{abstract}
In Bangladesh, food sold at local markets are usually not kept under hygienic conditions leading to contamination with different microorganisms and deterioration of food quality. This study was carried out to examine the microbial quality of prawns sold at local markets. Prawn samples collected from different markets were assessed for their bacteriological quality using the multiple tube fermentation technique to determine coliform count using the most probable number method in Brilliant Green Lactose Broth (BGLB) media. Positive tubes of the presumptive test were further cultured on Eosine Methylene Blue(EMB) and Mac Conkey agar media. The organisms isolated were further characterized using biochemical tests. Out of the 65 samples, $47(72.3 \%)$ showed positive results in all 3 tubes of dilution series using inoculum quantities of 1, 0.1 and $0.01 \mathrm{~g}$.Among 65 samples 57 samples that contained at least one positive in each dilution series were further re-identified with biochemical tests.This study showed 56.14\% \% isolates were Escherichia coliwhich conformed to expected biochemical reactions, formed round, small,elevated colonies with pink pigmentation on Mac Conkey agar media and round, small colonies with metallic green sheen pigmentation on EMB agar media. Other bacteria which presumptively appeared to be enterics and were isolated from BGLB were identified asKlebsiellapneumoniae(29.82\%),Staphylococcus aureus $(8.7 \%)$, Enterobacter aeroginosa $(3.5 \%)$ and Salmonellatyphimurium $(1.75 \%)$.Presumptive identification of $E$. coli in prawn in order to determine fecal contamination was able to identify $3 / 4$ of BGLB tubes with actual occurrence of $E$. coli. From this study it has been found that $\mathbf{9 7 . 1 4 \%}$ bacteria were sensitive to Co-Trimoxazole, compared to other antibiotics used in this test whereas only $\mathbf{3 7 . 1 4} \%$ bacteria were sensitive to nitrofurantoin. This study also highlighted the fact that prawns act as a major source of $E$. coli which indicates possible fecal contamination as well as presence of potentially pathogenic $E$. coliand these bacteria are resistant at a great percentage to almost all of these antibiotics used in this study. Prawns must therefore be cooked adequately before consumption.
\end{abstract}

Key words: Brilliant Green Lactose Broth (BGLB),Eosine Methylene Blue (EMB), Mac Conkey agar,Escherichia coli,Staphylococcus aureus,Klebsiella pneumonia,Enterobacter aeroginosa and Salmonellatyphimurium,Antibiotic resistance

\section{Introduction}

Fisheries are one of the major protein contributing source of Bangladesh, contributing $3.74 \%$ of our GDP and $22.23 \%$ of agricultural sector ${ }^{1}$.Bangladesh is a sea food exporting country and exports mainly frozen shrimps, fresh water fishes and marine water fishes to Japan,USA,Europe,Saudi Arabia,the UAE and Gulf States ${ }^{2}$.Now export market of Bangladesh is threatened for inadequate processed foods which may be contaminated by decomposition, high bacterial load,filth, unexpected foreign matters as well aspathogenic microbes (E.coli, Salmonella, V.cholerae etc.).

E. coli is a common bacteria found in the human intestine. Under certain conditions, E. coli can become pathogenic i.e. it gains the ability to cause disease. As the bacterium is adapted to conditions in the intestine, its occurrence in the environment indicates recent fecal shedding from the body.Moreover,as the environmental conditions are significantly different from what exists in the human intestine, E. coli fails to survive long outside of the human host. For these reasons, E. coli has been used as an indicator of recent fecal contamination and represents a threat to human and environmental health ${ }^{3}$.For a long time $E$. coli has become a common resident of the environment. Many of these are multi-drug resistant, having acquired the resistance determinant while residing in the human body or in the environment. Antibiotics are extensively used as growth promoters in poultry production or to control infectious disease. Anti-microbial abuse is considered to be the most vital selecting force to antimicrobial resistance of bacteria ${ }^{4-5}$.Moreover, antibiotic treatment is considered the most important issue that promotes the emergence, selection and spreading of antibiotic resistant microorganisms in both veterinary and human medicine ${ }^{6-}$ ${ }^{7}$.It was stated by well established evidence that antibiotics can lead to the emergence and dissemination of resistant $E$. coli which can then be passed into people via food or direct contact with

*Corresponding author:

Dr. Sunjukta Ahsan, Department of Microbiology, University of Dhaka, Dhaka 1000, Bangladesh, Phone: 01948283983, Email: Sunjukta@du.ac.bd 
infected animals. These resistant microbes may function as a potential source in the transportation of antimicrobial resistance to human pathogens ${ }^{8-9}$. However, once a pathogenics/ commensal strain enters a particular environment, it may change its property and survivability owing to gene transfer between pathogenic and non-pathogenic forms.Contaminated fruits, vegetables and water have been linked to E. coli 0157:H7 outbreaks ${ }^{10}$. In the United States, the first reported drinking water outbreak of $E$. coli 0157:H7 infections occurred in rural Missouri ${ }^{11}$. These outbreaks have led to the increased use of antibiotics to treat infections. The use of antibiotics in medicine and their applications in animal husbandry has brought about phenotypic changes, often due to chromosomal mutations and antibiotic resistance in E. coli has been globally identified in isolates from environmental, animal and human sources ${ }^{12}$.E.coli is the cause of $80-85 \%$ of urinary tract infections with Staphylococcus saprophyticus being the cause in $5-10 \%{ }^{13}$. With its range of pathologies, E.coli is a major cause of human morbidity and mortality around the world. Each year E.coli causes more than two million deaths due to infant diarrhoea ${ }^{14-15}$ and extraintestinal infections (mainly septicaemia derived from urinary tract infection) and is also responsible for approximately 150 million cases of uncomplicated cystitis ${ }^{16}$. Since humans and food animals carry so many E.coli cells that may establish commensal or antagonistic interactions with their hosts it is mandatory to define the genetic and population determinants that derive commensal strains to adopt a pathogenic behaviour. Kingeet al (2010) ${ }^{17}$ report E. coli that has been linked to well known antibiotic resistance gene pools and these genes can be transferred into the normal flora of humans and animals, where they exert a strong selective pressure for the emergence and spread of resistantE.coli strains ${ }^{17}$.Moreover,the faecal coliform as $E$. coli are generally considered as indisputable indicators of faecal contamination from warm blooded animal ${ }^{18}$. Antimicrobial resistance is an increasingly global problem and emerging antimicrobial resistance has become a public health issue worldwide ${ }^{19}$. A variety of foods and environmental sources harbor bacteria that are resistant to one or more antimicrobial drugs used in human or veterinary medicine and in food-animal production ${ }^{20-21}$. The World Health Organization states that antibiotic resistance is "a growing public health threat of broad concern that threatens the achievements of modern medicine." Emergence and spread of antibiotic resistance has become a global health threat and is often linked with overuse and misuse of clinical and veterinary chemotherapeutic agents. Modern industrial-scale animal feeding operations rely extensively on veterinary pharmaceuticals, including antibiotics to augment animal growth. This study also showed that prawns are the reservoirs of E. coli which act as a source of possible fecal contamination and the presence of potentially pathogenic E. coliwhich showed resistance to different types of antibiotics.

\section{Materials and Method}

Sample collection: The prawn samples were collected from two different local markets of Dhaka city named 'Ananda Bazar' and 'PolashiBazar' near to Dhaka University area.
Study area:The investigation was carried out at Environmental Microbiology Lab ofDepartment of Microbiology, University of Dhaka.

\section{Primary identification of Escherichia coli}

\section{Presumptive identification by MPN method}

Ten gram of prawn samples were blended for 2 minutes with 90 $\mathrm{ml}$ of Phosphate Buffered Saline (PBS) in an automatic blender. In Most Probable Number method a series of tubes containing selective BGLB media were inoculated with test portion of prawn samples using inoculum quantities of $1,0.1$ and $0.01 \mathrm{~g}$ and incubated at $37^{\circ} \mathrm{C}$. Each tubes containing gas with yellow color was regarded as - presumptive positive $\mathrm{C}$ for Coliform. Subsequent confirmatory test with selective Eosine Methylene Blue (EMB) and MacConkey agar media wasperformed.

Confirmative identification on EMB andMac Conkey agar media A loopful of culture from positive BGLB medium from each dilution was streaked on EMB and Mac Conkey agar media for confirmative identification of the samples. The plates were incubated at $37^{\circ} \mathrm{C}$ for $24 \mathrm{hrs}$. Colonies with metallic green sheen on EMB and round, small,convex colonies with pink pigmentation on MacConkey agar were thought to be Escherichia coli and picked as positive isolates for further identification.

\section{Biochemical tests}

The laboratory biochemical tests likeKligler $3 / 4$ S Iron Agar (KIA) test,Indole production test,Citrate utilization test,Methyl-red test and Voges-Proskauer (V.P.) test were used to confirm the identification of the selected colony from EMB and MacConkey agar media. Specific biochemical reactions such as fermentative metabolism, utilization of glucose, lactose, production of gases helped to identify Escherichia coli.

\section{Antibiotic Susceptibility Test}

Bacteria were streaked from glycerol broth stocks on to NA and incubated at $37^{\circ} \mathrm{C}$ for $24 \mathrm{hrs}$. Next day the bacteria were streaked from NA on to EMB agar and incubated at 37 for $24 \mathrm{hrs}$. A single colony was inoculated into $4 \mathrm{ml} \mathrm{MHB}$ within sterile vials from these EMB or Mac Conkey agar plates and incubated at 37 for $4 \mathrm{hrs}$. The loop was burned every time before and after inoculating the culture to maintain sterility. The turbidity of actively growing cultures in fresh MHB was adjusted to obtain the turbidity of McFarland 0.5 standard. From these bacteria were spread in the form of a lawn onto MHA plates containing disks of antibiotics like Ceftriaxone (CRO30), Cefixime (CFM5), Chloramphenicol (C30), Cotrimoxazole (COT25), Gentamicin(Gen10), Ciprofloxacin(CIP5), Tetracycline(TE30), Azithromycin(AZM15), Nitrofurantoin (F-300) and Amoxycillinclavulanic acid (AMC30). The disks were placed over the lawn of MHA with a sterile applicator. The applicator was burned each time before placing the disks on to the bacterial lawns for sterility. After that the plates were incubated at 37 for $24 \mathrm{hrs}$. Next day the plates were observed to determine the effect of the antibiotics. 


\section{Results and Discussion}

Out of the 65 samples, 47 (72.3\%) showed results indicating the presence of lactose-fermenter and gas-producer in all 3 tubes of dilution series using inoculum quantities of $1.0,0.1$ and $0.01 \mathrm{~g}$ (Figure 1).

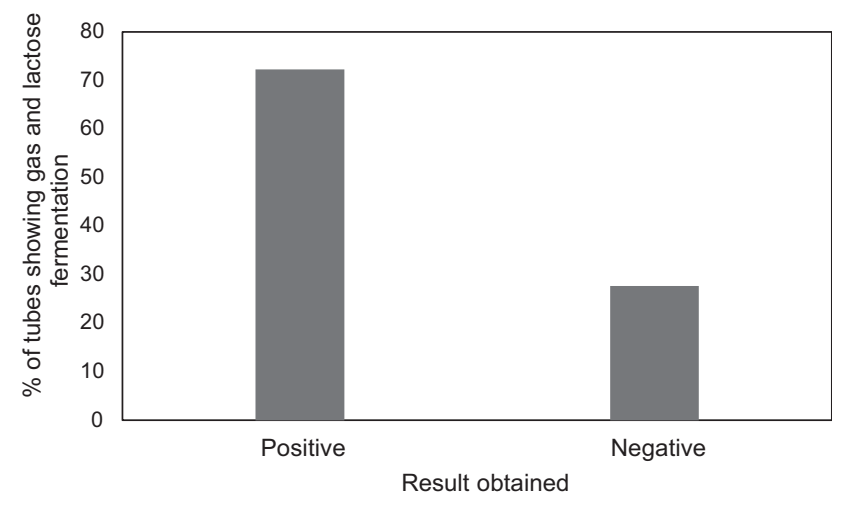

Figure 1. Result of 3 tubes dilution series (MPN) using inoculum quantities of 1.0, 0.1 and $0.01 \mathrm{~g}$

Among 65 samples 57 samples that contained at least one positive in each dilution series were further re-identified with biochemical tests. This study showed (56.14\%) isolates were Escherichia coli which conformed to expected biochemical reactions, formed round, small,elevated colonies with pink pigmentation on Mac Conkey agar media and round, small colonies with metallic green sheen pigmentation on EMB agar media. Other bacteria which presumptively appeared to be enterics and were isolated from BGLB were Klebsiellapneumoniae (29.82\%), Staphylococcus aureus( $(8.7 \%)$, Enterobacter aeroginosa(3.5\%) and Salmonella typhimurium (1.75\%)(Figure 2).

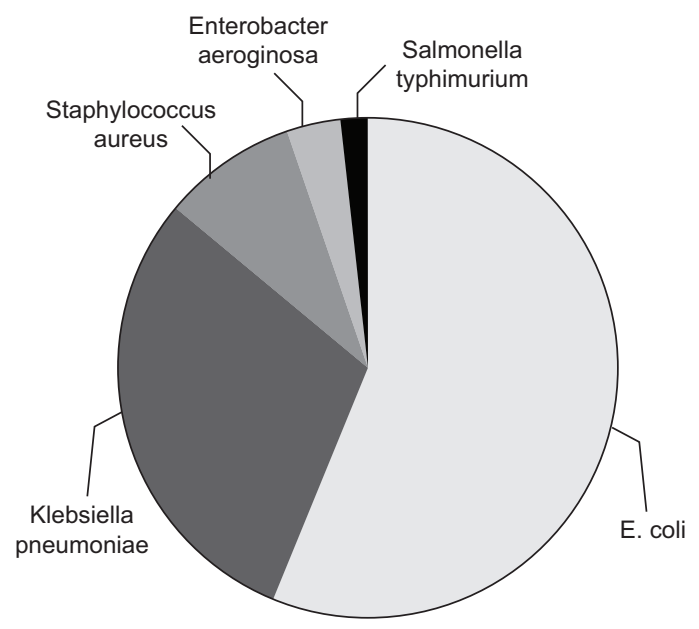

Figure 2. Identification of bacteria with biochemical tests

Table 1 showed that $97.14 \%$ bacteria were sensitive and $0.01 \%$ were intermediate to Co-Trimoxazole, $85.71 \%$ bacteria were sensitive to both Azithromycin and Chloramphenicol, $8.58 \%$ were intermediate to Azithromycin and $11.43 \%$ were intermediate to chloramphenicol, $77.14 \%$ bacteria were sensitive and $5.72 \%$ were intermediate to tetracycline, $74.28 \%$ bacteria were sensitive and $17.15 \%$ were intermediate to ciprofloxacin, $68.57 \%$ bacteria were sensitive to both ceftriaxone and Cefixime whereas $28.57 \%$ were intermediate to ceftriazone, $14.29 \%$ were intermediate to Cefixime, $62.85 \%$ bacteria were sensitive to both Gentamicin and Amoxycillin-Clavulanic acid, $28.58 \%$ were intermediate to Amoxycillin Clavulanic acid, $25.72 \%$ were intermediate to Gentamicin and $37.14 \%$ bacteria were sensitive and $37.15 \%$ were intermediate to nitrofurantoin.In a study comparing $E$. coli concentrations in waters from agricultural and "pristine" sites, contamination was found in both settings. Furthermore,recent environmental surveys repeatedly have recovered substantial E.coli populations from soils and fresh water habitats ${ }^{22-23}$ indicating that naturalized (innocuous) strainsmay be widespread in nature.In this study it was found that $56.14 \%$ ofthe prawn sampleshad $E$. coli and the percentage of this bacteria was highest compared to other bacteria.Bacterial resistance to antibiotics increasingly hinders treatment of life-threatening illnesses. Misuse and overuse of antibiotics plays a crucial role in the development of resistance and there is evidence that agricultural use of antibiotics is a contributor to the aggregation of resistance in the environment ${ }^{24-}$ ${ }^{25}$.Following excretion, antibiotics are transported through the environment via runoff, leaching and land application of manure; however, airborne transport from feed yards has not been characterized ${ }^{26}$. Likewise we have found a great percentage of resistant E.colifrom prawn samples.

Table 1. Results of antibiotic susceptibility tests

\begin{tabular}{lcccc}
\hline Antibiotics & $\begin{array}{c}\text { Disc } \\
\text { content }(\mu \mathrm{g})\end{array}$ & $\begin{array}{c}\text { Sensitivity } \\
(\%)\end{array}$ & $\begin{array}{c}\text { Intermediate } \\
(\%)\end{array}$ & $\begin{array}{c}\text { Resistance } \\
(\%)\end{array}$ \\
\hline Nitrofurantoin & 300 & 37.14 & 37.15 & 25.71 \\
Amoxycillin & 30 & 62.85 & 28.58 & 8.57 \\
Clavulanic acid & & & & \\
Azithromycin & 15 & 85.71 & 8.58 & 5.71 \\
Ceftriaxone & 30 & 68.57 & 28.57 & 2.86 \\
Chloramphenicol & 30 & 85.71 & 11.43 & 2.86 \\
Cefixime & 5 & 68.57 & 14.29 & 17.14 \\
Co-Trimoxazole & 25 & 97.14 & 0.01 & 2.85 \\
Gentamicin & 10 & 62.85 & 25.72 & 11.43 \\
Ciprofloxacin & 5 & 74.28 & 17.15 & 8.57 \\
Tetracycline & 30 & 77.14 & 5.72 & 17.14 \\
\hline
\end{tabular}

\section{Acknowledgements}

The author would like to express thanks to the Department of Microbiology, University of Dhaka for laboratory facilities.

\section{References}

1. Do F.2001. Fisheries resources information of Bangladesh In: Sharnika (Motsha Shaptaho-2001). Ministry of Fisheries and Livestock, Peoples Republic of Bangladesh. pp:65-76.

2. BFFEA (Bangladesh Frozen Food Export Association), 2010. Bangladesh exports statistics, Dhaka, Bangladesh.

3. Hartstra AV, Bouter KEC, Backhed F and Nieuwdorp M. 2015. Insights into the role of the microbiome in obesity and type 2 diabetes. Diabetes care. 38(1): 159-165. 
4. Moreno MA, Dominguez L, Teshoger T, Herrero IA and Perrere ME. 2000. Antibiotic resistances monitoring. The Spanish programme. Int $J$. Antimicrob. Agents.14: 285-290.

5. Okeke IN, Lamikanra A and Edelman R. 1999. Socioeconomic and behavioral factors leading to acquired bacterial resistance to antibiotics in developing countries. Emerg. Infect. Dis. 5: 13-27.

6. Neu HC. 1992. The crisis in antibiotic resistance. Science. 257: 1064-73.

7. Witte W. 1998. Medical consequences of antibiotic use in agriculture. Science. 279: 996-97.

8. Van de Boogard AE and Stobberingh EE. 2000. Epidemiology of resistance to antibiotics links between animals and humans. Int. J. Antimicrob. Agents. 14: 327-335.

9. Schroeder CM, Zhao C, Debroy C, Torcolini J, Zhao J and White DG. 2002. Antimicrobial resistance of Escherichia coli 0157:H7 isolated from humans, cattle, swine and food. Appl. Environ.Microbiol. 68: 576-581.

10. Ferens WA and Hovde CJ. 2011. Escherichia coli O157:H7: animal reservoir and sources of human infection. Food borne Pathog. Dis. 8: 465-487.

11. Swerdlow DL, Woodruff BA, Brady RC, Griffin PM, Tippen S and Donnell HD. 1992. A waterborne outbreak in Missouri of Escherichia coli O157:H7 associated with bloody diarrhea and death. Ann. Intern. Med. 117: 812-819.

12. World Health Organization (WHO). Public Health Importance of Antimicrobial Resistance. Availableonline: http://www.who.int/ drugresistance/AMR_Importance/en/ (accessed on 4 May 2014).

13. Nicolle LE.2003. Urinary tract infection: traditional pharmacologic therapies. Dis. Mon. 49: 111-28.

14. Kotloff KL, Winickoff JP, Ivanoff B, Clemens JD and Swerdlow DL. 1999. Global burden of Shigella infections: implications for vaccine development and implementation of control strategies. Bull. World Health Organ. 77: 651-66.

15. Kosek M, Bern C and Guerrant RL. 2003. The global burden of diarrhoeal disease, as estimated from studies published between 1992 and 2000. Bull. World Health Organ. 81: 197-204.
16. Russo TA and Johnson JR.2003. Medical and economic impact of extraintestinal infections due to Escherichia coli: focus on an increasingly important endemic problem. Microbes Infect. 5: 449-456.

17. Kinge NW, Ateba CN and Kawadza DT. 2010. Antibiotic resistance profiles of Escherichia coli isolated from different water sources in the Mmabatho locality, North-West province, South Africa. S. Afr. J. Sci. 106: 44-49.

18. Ward DR and Hackney C.1991. Microbial load in shrimp. In: Processing of PACON sustainable aquaculture, Hawaii. 95: 308-316.

19. Kaye KS, Engemann JJ, Fraimow HS and Abrutyn E. 2004. Pathogens resistant to antimicrobial agents: Epidemiology, molecular mechanisms and clinical management. Infect. Dis.Clin.North Am. 18: 467-511.

20. Bager F and Helmuth R. 2001. Epidemiology of resistance of quinolones in Salmonella. Vet. Res. 32: 285-290.

21. Anderson AD, Nelson JM, Rossiter S and Angulo FJ. 2003. Public health consequences of use of antimicrobial agents in food animals in the United States. Microb. Drug Resist. 9: 373-379.

22. Walk ST, Alm EW, Gordon DM, Ram JL, Toranzos GA, Tiedje JM and Whiiam TS.2009. Cryptic lineages of the genus Escherichia. Appl. Environ. Microbiol. 75: 6534-6544.

23. Ishii S, Ksoll WB, Hicks RE and Sadowsky MJ. 2006. Presence and growth of naturalized Escherichia coli in temperate soils from Lake Superior watersheds. Appl. Environ. Microbiol. 72: 612-621.

24. Gilchrist MJ, Greko C, Wallinga DB, Beran GW, Riley DG and Thorne PS. 2007. The potential role of concentrated animal feeding operations in infectious disease epidemics and resistance. Environ. Health Perspect. 115: 313-316.

25. Levy SB and Marshall B. 2004. Antibacterial resistance worldwide: causes, challenges and responses.Nat. Med. 10:S122-S129.

26. Andrew D. McEachran, Brett R. Blackwell, J. Delton Hanson, Kimberly J. Wooten, Gregory D, Mayer, Stephen B. Cox, and Philip N. Smith. 2015. Antibiotics, Bacteria, and Antibiotic Resistance Genes: Aerial Transport from Cattle Feed Yards via Particulate Matter. Environ. Health Perspect. 123: $337-343$. 